\title{
Greater body mass index is a better predictor of subclinical cardiac damage at long-term follow-up in men than is insulin sensitivity: a prospective, population-based cohort study
}

\author{
Mette Lundgren Nielsen ${ }^{1 *}$, Manan Pareek1, Oke Gerke², Margrét Leósdóttir ${ }^{3}$, Peter M. Nilsson ${ }^{4}$ \\ and Michael Hecht Olsen ${ }^{1,5}$
}

\begin{abstract}
Background: To examine whether lower insulin sensitivity as determined by homeostatic model assessment (HOMA-\%S) was associated with increased left ventricular mass (LVM) and presence of LV diastolic dysfunction at long-term follow-up, independently of body mass index (BMI), in middle-aged, otherwise healthy males.

Methods: Prospective population-based cohort study with a median (IQR) follow-up time of 28 (27-28) years, in which traditional cardiovascular risk factors, including $\mathrm{HOMA}-\% \mathrm{~S}$ and $\mathrm{BMI}$, were assessed at baseline, and echocardiographic determination of LVM and LV diastolic function was performed at follow-up. Associations between risk factors and echocardiographic variables were tested using multivariable linear and binary logistic regression.

Results: The study population comprised 247 men with a median (IQR) age of 47 (47-48) years. Mean (SD) BMI was $25.1+/-3.0 \mathrm{~kg} / \mathrm{m}^{2}$, and median (IQR) HOMA-\%S was 113.0 (68.3-284.6). Subjects with low insulin sensitivity (lowest HOMA-\%S quartile (Q1)) had significantly greater BMI, fasting plasma insulin, and higher fasting blood glucose (FBG) ( $p<0.02$ for all). BMI and HOMA-\%S were significantly correlated ( $r=-0.383, p<0.0001)$. At follow-up, mean (SD) LVM and LVMI were $202+/-61 \mathrm{~g}$ and $103+/-31 \mathrm{~g} / \mathrm{m}^{2}$, respectively, whereas median (IQR) E/é was 10 (8-12). Moreover, $36 \%$ had grade 2 or 3 diastolic dysfunction. In multivariable analyses, greater BMI, but not low insulin sensitivity was independently associated with later detection of increased LVM and diastolic dysfunction.
\end{abstract}

Conclusion: Greater baseline BMI, but not lower insulin sensitivity was independently associated with greater LVM and diastolic dysfunction at long-term follow-up.

Keywords: Diastolic dysfunction, Homeostatic model assessment, Insulin sensitivity, Body mass index, Left ventricular mass, Prospective cohort study

\footnotetext{
* Correspondence: mettelundgren@gmail.com

${ }^{1}$ Cardiovascular and Metabolic Preventive Clinic, Department of Endocrinology, Centre for Individualized Medicine in Arterial Diseases (CIMA), Odense University Hospital, Sdr. Boulevard 29, DK-5000 Odense, Denmark Full list of author information is available at the end of the article
} 


\section{Background}

Diastolic dysfunction of the left ventricle (LV) is characterized by delayed active relaxation and increased chamber stiffness [1]. The condition is most commonly associated with ischemic heart disease and/or hypertension with subsequent concentric remodeling or hypertrophy of LV (LVH) [2]. LV diastolic dysfunction and LVH are powerful independent predictors of future cardiovascular morbidity and mortality [3, 4], and identification of other hemodynamic and non-hemodynamic factors associated with the development of these often subclinical cardiac conditions may unveil novel targets for prevention.

Both LV diastolic dysfunction and LVH are common findings among patients with diabetes mellitus (DM) [5-7]. The associations are independent of concomitant hypertension and ischemic heart disease, which has led to the term diabetic cardiomyopathy, defined as ventricular dysfunction in a patient with DM, occurring independently of an otherwise recognized cause [8]. However, the pathogenic mechanisms for development of this condition are poorly understood. Insulin resistance and the accompanying hyperinsulinemia may constitute an important pathophysiological link in subjects with obesity, glucose intolerance, or overt DM, but the majority of studies so far have yielded inconsistent results, particularly due to inadequate adjustment for key confounders, notably body size, blood pressure, and glucose levels [9-11].

Additionally, most previous studies addressing this subject have been of cross-sectional nature, which, besides the inability to establish causality, are further limited by the fact that there is evidence to suggest that the changes in LV structure and function may be consequences of long-term, rather than short-term, metabolic abnormalities [12].

Therefore, we conducted this study in subjects free from DM and overt cardiovascular disease at baseline aiming to examine whether lower insulin sensitivity as determined by homeostatic model assessment (HOMA-\%S) was associated with increased left ventricular mass (LVM) and presence of LV diastolic dysfunction at long-term followup, independently of body mass index (BMI).

\section{Methods}

\section{Study population}

Study subjects were derived from the Malmö Preventive Project (MPP, 1974-1992, $n=33,346$ ), a populationbased cohort study aiming to screen for cardiovascular risk factors, alcohol abuse, and breast cancer among inhabitants in Malmö, Sweden, born between 1921 and 1949 [13]. All subjects answered a self-administered questionnaire on lifestyle, medical history, and current medication. Height and weight in light indoor clothing were measured, and body mass index (BMI) was calculated. Blood pressure was measured twice after $10 \mathrm{~min}$ of supine rest, with the mean value recorded for analysis. Moreover, blood samples were obtained after an overnight fast with measurement of blood glucose, plasma insulin, serum lipids, and serum creatinine. In 18,960 participants without prevalent DM, a 120 min oral glucose tolerance test (OGTT) was performed by a standard method (30 g/m $\mathrm{m}^{2}$ body surface area (BSA) in a $10 \%$ aqueous solution) [14]. A re-examination study (MPPRES, $n=18,238$ ) was conducted between 2002 and 2006. In a subsample of 1,792 individuals therefrom, an echocardiography and a 12-lead ECG recording were carried out. These subjects were randomly selected from groups defined by fasting plasma glucose (FPG), with oversampling in groups of subjects with impaired fasting glucose and DM, in order to ensure a sufficient number of individuals in each category. MPP and MPPRES were approved by the Ethics Committee of Lund University, Sweden and conducted in accordance with the Declaration of Helsinki. Written informed consent was obtained from all participants.

\section{Final study population}

Subjects with missing fasting blood glucose (FBG) and/or fasting plasma insulin measurements at baseline $(n=$ $26,057)$ were excluded from the present study. Remaining subjects with prevalent cardiovascular disease $(n=33)$, DM $(n=215)$, and/or other missing baseline variables $(n=13)$, were likewise excluded. Of the 7032 subjects left, 305 subjects had an echocardiography performed at follow-up, with 263 subjects potentially eligible for the current study (missing echocardiography variables, $n=42$ ). Since only 16 subjects were female, they were excluded as well, leaving a final study population comprising 247 males (Fig. 1). Relevant definitions are provided below.

\section{Investigations performed at baseline Prevalent cardiovascular disease or diabetes mellitus}

Prevalent cardiovascular disease was defined by the International Classification of Diseases (ICD-9 and ICD-10) codes gathered from the Swedish Hospital Discharge Registry as well as local hospital and study registries and encompassed previous myocardial infarction, transient ischemic attack, and stroke. Prevalent diabetes mellitus was defined as self-reported diabetes mellitus or according to the 1985 World Health Organization (WHO) criteria for DM by either FBG or during $120 \mathrm{~min}$ OGTT [15].

\section{Insulin sensitivity (HOMA-\%S)}

HOMA-\%S was derived via the computerized HOMAcalculator (@The University of Oxford 2004) using FBG and fasting plasma insulin (measured by standard radioimmunoassay) as input [16]. Based on sensitivity analyses 


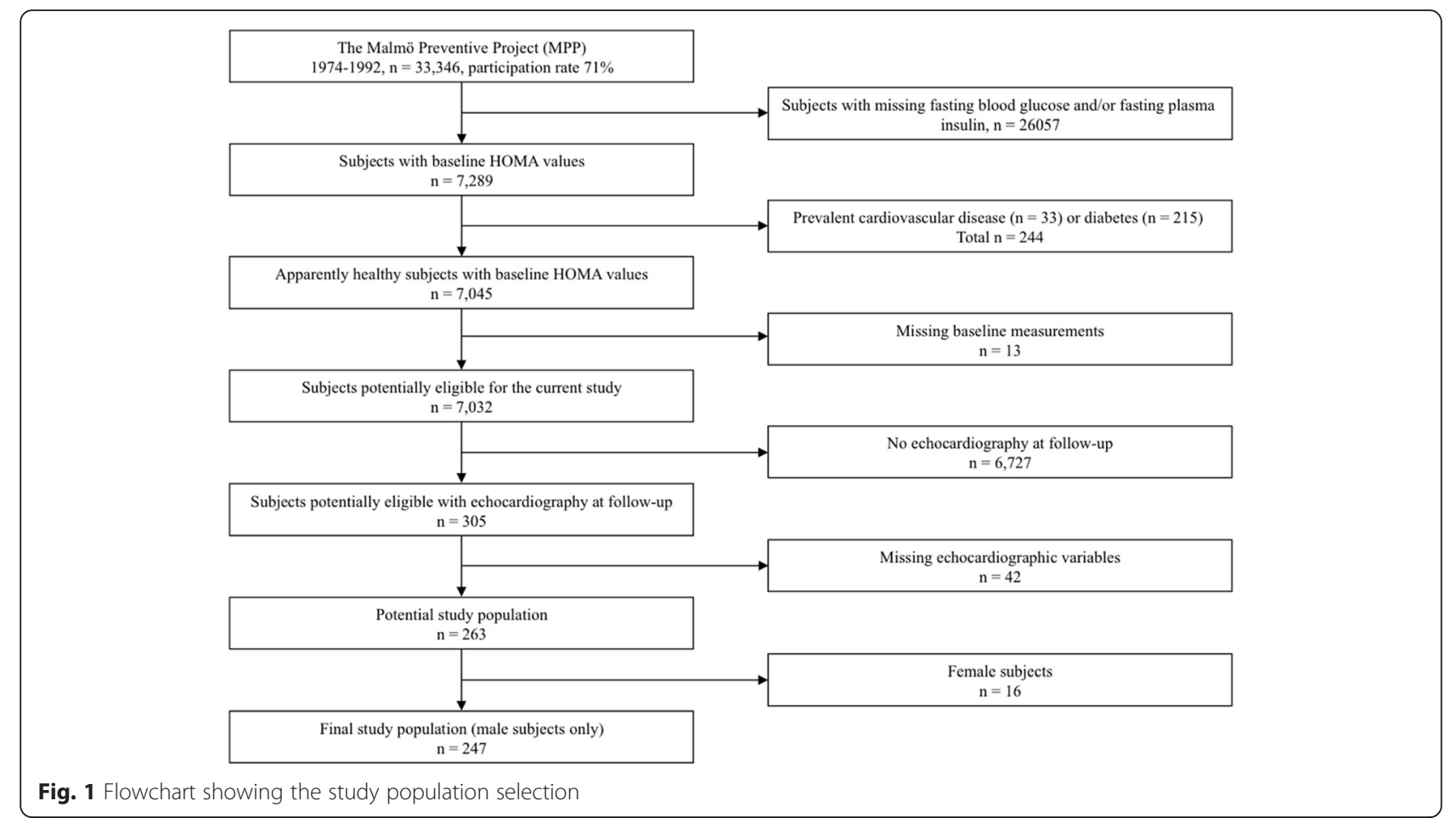

regarding LV diastolic dysfunction, low insulin sensitivity was defined as the lowest HOMA-\%S quartile (Q1), whereas quartiles 2-4 (Q2-4) were defined as normal insulin sensitivity.

\section{Investigations performed at follow-up Echocardiography}

Echocardiography was conducted with a 3V2c transducer (Acuson Sequoia, Mountain View, CA) or an S3 transducer (Sonos 5500 Philips, Andover, MA). LV ejection fraction (LVEF) was quantified visually. LVM calculations were based on 2-dimensional linear measurements in the parasternal long-axis view at the tips of the mitral valve leaflets at end-diastole, perpendicular to the long axis of LV. The thickness of the interventricular septum (IVS), LV internal diameter (LVID), and the thickness of the posterior wall (PW) were obtained by placing the calipers on the interface between myocardial wall and cavity and the interface between myocardial wall and pericardium, respectively. LVM was then calculated using the Cube formula recommended by the American Society of Echocardiography (ASE) and the European Association of Cardiovascular Imaging (EACVI), and indexed for BSA, obtaining LVMI [17]. LV diastolic function was assessed in the apical four-chamber view using transmitral pulsed Doppler flow with a $1-3 \mathrm{~mm}$ sample volume placed between the tips of the mitral valve leaflets (obtaining $\mathrm{E}, \mathrm{A}$, and E-wave deceleration time (DT)) and tissue
Doppler imaging with the sample volume positioned within $1 \mathrm{~cm}$ of the septal and lateral borders of the mitral annulus (obtaining both septal and lateral é and averaging the values for the analyses). A mean of 3-5 cycles was used. The intra- and interobserver variabilities are reported elsewhere [18]. Diastolic function was graded according to the recommendations of American Society of Echocardiography and European Association of Cardiovascular Imaging [19], using ageappropriate cut-off values of septal é, lateral é, E-wave DT, E/A, and averaged E/é. If septal é was $\geq 8$ and/or lateral é was $\geq 10$, subjects were classified as having normal diastolic function. If septal é was $<8$ and lateral é was $<10$, subjects were classified as having diastolic dysfunction, and the values of E-wave DT, E/A, and E/é were used for grading subjects into grade 1, 2 or 3 diastolic dysfunction, as previously described (Table 1) [20]. Equivocal cases, i.e. subjects who were in a

Table 1 Scheme for grading diastolic dysfunction

\begin{tabular}{lllll}
\hline & $\begin{array}{l}\text { Grade 0 } \\
\text { (normal) }\end{array}$ & $\begin{array}{l}\text { Grade 1 } \\
\text { (mild) }\end{array}$ & $\begin{array}{l}\text { Grade 2 } \\
\text { (moderate) }\end{array}$ & $\begin{array}{l}\text { Grade 3 } \\
\text { (severe) }\end{array}$ \\
\hline Septal é $(\mathrm{cm} / \mathrm{s})$ & $\geq 8$ & $<8$ & $<8$ & $<8$ \\
Lateral é $(\mathrm{cm} / \mathrm{s})$ & $\geq 10$ & $<10$ & $<10$ & $<10$ \\
E-wave DT (ms) & $140-240$ & $\geq 240$ & $140-240$ & $<140$ \\
E/A & $0.8-1.5$ & $<0.8$ & $0.8-1.5$ & $>1.5$ \\
E/é & $<9$ & $\leq 12$ & $\geq 9$ & $\geq 13$ \\
\hline
\end{tabular}


transitional state between grade 1 and 2 diastolic dysfunction with E/é $\geq 9$ and $\leq 12$, but E/A and E-wave DT pointing in opposite directions, were classified as undetermined diastolic dysfunction. If E/é was $>12$, subjects were classified as having either grade 2 or 3 diastolic dysfunction. Finally, all subjects with E/é $<9$ were classified as either normal (E-wave DT $<240 \mathrm{~ms}$ and $\mathrm{E} / \mathrm{A} \geq 0.8$ ) or grade 1 diastolic dysfunction (all other subjects), even if they did not strictly fulfill the primary é criteria for normal diastolic function. Grade 2 and 3 diastolic dysfunction were grouped together, since only two individuals fulfilled the criteria for grade 3 diastolic dysfunction.

\section{Statistical analysis}

Continuous variables were summarized by means and standard deviations (approximately normally distributed variables) and medians and interquartile ranges (IQR) (non-normally distributed variables), whereas categorical variables were presented by frequencies and corresponding percentages. Group-wise comparisons were performed using independent samples t-test, Mann-Whitney U-test, and Pearson's $X^{2}$-test or Fisher's exact test (depending on cell frequencies), respectively. The associations between risk factors and LVM, LVMI, or E/é, respectively, were assessed by multivariable linear regression. Since E/é was moderately positively skewed, the association between E/é and various risk factors was assessed by linear regression after natural log-transformation of E/é. The association between risk factors and diastolic function, i.e. normal or grade 1 diastolic dysfunction vs. grade 2 or 3 diastolic dysfunction, was assessed by binary logistic regression. Statistically and clinically significant variables were included in the final multivariable linear and binary logistic regression models, and stepwise subset selection was applied for adjustment of these models with a p-stay of 0.2 . The significance level for the univariable analyses was $5 \%$. In all cases, time elapsed from baseline inclusion to echocardiography at follow-up was included as an explanatory variable under the assumption that it could impact the severity of the echocardiographic findings. All analyses were carried out using IBM SPSS Statistics 22 (IBM, Armonk, New York, USA) and Stata/IC 13 (StataCorp LP, College Station, Texas, USA).

\section{Results}

\section{Characteristics of the study population}

After applying the aforementioned exclusion criteria, a study cohort of 247 subjects was left for analysis. At baseline, subjects were middle-aged with a median age of 47 (IQR 47-48) years, mean systolic blood pressure $129+/-15 \mathrm{mmHg}$, and borderline overweight with mean BMI $25.1+/-3.0 \mathrm{~kg} / \mathrm{m}^{2}$. Total cholesterol was mildly elevated at $5.7+/-1.0 \mathrm{mmol} / \mathrm{L}$. Median HOMA-
\%S was 113.0 (IQR 68.3-284.6). Subjects with low insulin sensitivity (HOMA-\%S Q1) had significantly greater BMI, fasting plasma insulin and both higher FBG and BG at $120 \mathrm{~min}$, borderline significantly greater systolic blood pressure, but there were no significant betweengroup differences regarding age, smoking status, and total cholesterol. BMI and HOMA-\%S were significantly correlated (Pearson's $r=-0.383, p<0.0001$ ). At followup, mean LVMI was $103+/-31 \mathrm{~g} / \mathrm{m}^{2}$, and median E/é was 10 (IQR 8-12). Moreover, $36 \%$ (when excluding the 20 subjects with undetermined diastolic dysfunction) had grade 2 or 3 diastolic dysfunction. Subjects with low insulin sensitivity had a borderline significantly greater prevalence of grade 2 or 3 diastolic dysfunction, whereas there was no significant between-group difference with respect to LVEF. Tables 2 and 3 show the baseline characteristics of the subjects categorized according to HOMA-\%S category and diastolic function, respectively. Furthermore, Additional file 1: Table S1 shows the baseline characteristics according to BMI category, i.e. non-overweight vs. overweight or obese subjects.

\section{Left ventricular size}

There were no significant differences in neither LVM $\left(205+/-61 \mathrm{~g} / \mathrm{m}^{2}\right.$ vs. $\left.201+/-61 \mathrm{~g} / \mathrm{m}^{2}, p=0.7\right)$ nor LVMI $\left(103+/-30 \mathrm{~g} / \mathrm{m}^{2}\right.$ vs. $\left.103+/-30 \mathrm{~g} / \mathrm{m}^{2}, p=0.9\right)$ between subjects with low vs. normal insulin sensitivity according to HOMA-\%S. In univariable analyses, higher values of both LVM and LVMI were significantly associated with higher BMI, but not HOMA-\%S category. The adjusted multivariable linear regression models are presented in Tables 4 and 5 and included only BMI, whereas age and HOMA-\%S category were forced into the models. Smoking status, systolic blood pressure, total cholesterol, fasting plasma insulin, creatinine, and sedentary lifestyle were not significantly associated with LVM or LVMI on univariable analyses and therefore not included in the final multivariable regression models. We did not detect any significant interactions regarding HOMA-\%S. Furthermore, the results were not affected by BMI alterations during follow-up, i.e. whether the individuals gained or lost weight, even when stratified for whether or not they where initially overweight (results not shown, available upon request).

\section{Diastolic function}

There was no significant difference in E/é according to HOMA-\%S category (Q1: median 10 (IQR: 8-12) vs. Q24 median: 10 (IQR: $7-12$ ), $p=0.2$ )), whereas grade 2 or 3 diastolic dysfunction was borderline significantly more prevalent among subjects with low vs. normal HOMA-\%S ( $47 \%$ vs. $33 \%, p=0.06$ ). In univariable analyses, higher $\mathrm{E} /$ é was associated with higher age, BMI, serum creatinine, and shorter follow-up time, while diastolic dysfunction 
Table 2 Baseline characteristics according to HOMA-S category. Similar variables, obtained at follow-up, are depicted for comparison

\begin{tabular}{|c|c|c|c|c|}
\hline Variable & $\begin{array}{l}\text { All subjects } \\
(n=247)\end{array}$ & $\begin{array}{l}\text { HOMA-S Q1 } \\
(n=63)\end{array}$ & $\begin{array}{l}\text { HOMA-S Q2-4 } \\
(n=184)\end{array}$ & $\begin{array}{l}\text { P-value for difference between } \\
\text { HOMA-S categories }\end{array}$ \\
\hline \multicolumn{5}{|l|}{ Baseline MPP } \\
\hline Age (years) & $47[47-48]$ & $47[47-48]$ & $47[47-48]$ & $0.1^{c}$ \\
\hline Active smoking & $118(48 \%)$ & $27(43 \%)$ & $91(50 \%)$ & $0.4^{\mathrm{a}}$ \\
\hline $\mathrm{BMI}\left(\mathrm{kg} / \mathrm{m}^{2}\right)$ & $25.1+/-3.0$ & $26.9+/-3.8$ & $24.5+/-2.4$ & $<0.0001^{\mathrm{b}}$ \\
\hline Systolic blood pressure $(\mathrm{mmHg})$ & $129+/-15$ & $133+/-19$ & $128+/-14$ & $0.0502^{b}$ \\
\hline Total cholesterol (mmol/L) & $5.7+/-1.0$ & $5.9+/-1.3$ & $5.7+/-0.9$ & $0.2^{\mathrm{b}}$ \\
\hline Creatinine $(\mu \mathrm{mol} / \mathrm{L})$ & $93+/-13$ & $93+/-13$ & $92+/-13$ & $0.7^{\mathrm{b}}$ \\
\hline $\mathrm{FBG}(\mathrm{mmol} / \mathrm{L})$ & $5.1+/-0.5$ & $5.2+/-0.6$ & $5.0+/-0.5$ & $0.02^{b}$ \\
\hline Fasting insulin (pmol/L) & $48[18-78]$ & 108 [90-144] & $36[18-54]$ & $<0.0001^{\mathrm{C}}$ \\
\hline HOMA-\%B & $83.2[54.4-124.2]$ & $147.2[118.8-184.4]$ & $67.3[47.8-92.1]$ & $<0.0001^{c}$ \\
\hline HOMA-\%S & $113.0[68.3-284.6]$ & $50.2[37.1-61.9]$ & $150.7[99.3-289.7]$ & $<0.0001^{c}$ \\
\hline Sedentary lifestyle & $143(58 \%)$ & $38(60 \%)$ & $105(57 \%)$ & $0.7^{\mathrm{a}}$ \\
\hline Antihypertensive medication & $11(5 \%)$ & $4(6 \%)$ & $7(4 \%)$ & $0.4^{\mathrm{a}}$ \\
\hline \multicolumn{5}{|l|}{ MPP re-examination } \\
\hline Age (years) & $74[70-75]$ & $74[70-75]$ & $74[71-75]$ & $0.5^{c}$ \\
\hline Active smoking & $33(13 \%)$ & $8(13 \%)$ & $25(14 \%)$ & $0.9^{\mathrm{a}}$ \\
\hline $\mathrm{BMI}\left(\mathrm{kg} / \mathrm{m}^{2}\right)$ & $27.9+/-3.6$ & $28.3+/-4.3$ & $27.8+/-3.3$ & $0.3^{b}$ \\
\hline Systolic blood pressure $(\mathrm{mmHg})$ & $149+/-21$ & $146+/-18$ & $149+/-21$ & $0.3^{b}$ \\
\hline Total cholesterol (mmol/L) & $5.1+/-1.1$ & $4.7+/-1.0$ & $5.2+/-1.1$ & $0.001^{b}$ \\
\hline FPG (mmol/L) & $7.1+/-2.1$ & $7.4+/-2.0$ & $7.0+/-2.1$ & $0.1^{\mathrm{b}}$ \\
\hline LVM (g) & $202+/-61$ & $205+/-61$ & $201+/-61$ & $0.7^{b}$ \\
\hline $\operatorname{LVMI}\left(\mathrm{g} / \mathrm{m}^{2}\right)$ & $103+/-30$ & $103+/-30$ & $103+/-30$ & $0.9^{\mathrm{b}}$ \\
\hline $\mathrm{EF}(\%)$ & $60+/-8$ & $60+/-8$ & $60+/-8$ & $0.5^{b}$ \\
\hline Grade 2 or 3 diastolic dysfunction & $82(36 \%)$ & $27(47 \%)$ & $55(33 \%)$ & $0.06^{\mathrm{a}}$ \\
\hline E/é & $10[8-12]$ & $10[8-12]$ & $10[7-12]$ & $0.3^{c}$ \\
\hline Time (years) & $28[27-28]$ & $28[25-29]$ & $28[27-28]$ & $0.4^{c}$ \\
\hline
\end{tabular}

Categorical variables (active smoking, grade 2 or 3 diastolic dysfunction) are given as $\mathrm{n}(\%)$, whereas continuous variables are given as mean $+/-$ SD (approximately normally distributed variables, i.e. body mass index (BMI), systolic blood pressure, total cholesterol, creatinine, fasting blood glucose (FBG), fasting plasma glucose (FPG), left ventricular mass (LVM), left ventricular mass index (LVMI), ejection fraction (EF)) or median (IQR) (non-normally distributed variables, i.e. age, fasting insulin, HOMA-\%S, HOMA-\%B, E/é, and time)

${ }^{\mathrm{a}}$ Pearson's $\mathrm{X}^{2}$-test; ${ }^{\mathrm{b}}$ independent samples t-test; ${ }^{\mathrm{C}}$ Mann-Whitney $\mathrm{U}$ test

was associated with higher BMI and shorter follow-up time, but not serum creatinine. The adjusted multivariable regression models are shown in Tables 6 and 7. In both cases, HOMA-\%S was forced into the models. Smoking status, systolic blood pressure, total cholesterol, fasting plasma insulin, and sedentary lifestyle were not significantly associated with E/é or the presence of diastolic dysfunction on univariable analyses and therefore not included in the multivariable regression models. No significant interactions were detected with respect to HOMA-\%S. Regarding BMI changes, the same was true as for LV size (results not shown, available upon request).

\section{Discussion}

In this prospective population-based cohort study comprising middle-aged male, apparently healthy subjects, we found that greater BMI, but not lower insulin sensitivity defined as the lowest HOMA-\%S quartile was associated with later detection of increased LVM and grade 2 or $3 \mathrm{LV}$ diastolic dysfunction. Low insulin sensitivity (HOMA-\%S Q1) was only associated later recognition of grade 2 or $3 \mathrm{LV}$ diastolic dysfunction in univariable analysis, but the association was lost after adjusting for BMI. As expected, BMI and HOMA-\%S were significantly correlated.

Conflicting results have been reported regarding the relationship between insulin sensitivity and both indexed and non-indexed LVM, and to our knowledge, none of these were prospective. In a small study comprising 29 non-obese, glucose-tolerant subjects with borderline hypertension, Phillips et al. found a significant independent association between LVMI and insulin sensitivity 
Table 3 Baseline characteristics according to diastolic function. Similar variables, obtained at follow-up, are depicted for comparison

\begin{tabular}{|c|c|c|c|c|}
\hline Variable & $\begin{array}{l}\text { All subjects } \\
(n=227)\end{array}$ & $\begin{array}{l}\text { Normal or grade } 1 \text { diastolic } \\
\text { dysfunction }(n=145)\end{array}$ & $\begin{array}{l}\text { Grade } 2 \text { or } 3 \text { diastolic } \\
\text { dysfunction }(n=82)\end{array}$ & $\begin{array}{l}P \text {-value for difference between } \\
\text { diastolic dysfunction categories }\end{array}$ \\
\hline \multicolumn{5}{|l|}{ MPP baseline } \\
\hline Age (years) & $47[47-48]$ & $47[47-48]$ & $47[47-48]$ & $0.5^{c}$ \\
\hline Active smoking & 109 (48 \%) & $73(50 \%)$ & $36(44 \%)$ & $0.4^{\mathrm{a}}$ \\
\hline $\mathrm{BMI}\left(\mathrm{kg} / \mathrm{m}^{2}\right)$ & $25.1+/-3.1$ & $24.7+/-3.0$ & $25.9+/-3.1$ & $0.003^{b}$ \\
\hline Systolic blood pressure (mmHg) & $129+/-15$ & $129+/-16$ & $129+/-15$ & $0.7^{\mathrm{b}}$ \\
\hline Total cholesterol (mmol/L) & $5.7+/-1.0$ & $5.7+/-0.9$ & $5.7+/-1.2$ & $0.8^{b}$ \\
\hline Creatinine $(\mu \mathrm{mol} / \mathrm{L})$ & $92+/-13$ & $91+/-12$ & $94+/-14$ & $0.09^{b}$ \\
\hline FBG (mmol/L) & $5.1+/-0.5$ & $5.1+/-0.5$ & $5.1+/-0.5$ & $0.6^{\mathrm{b}}$ \\
\hline Fasting insulin (pmol/L) & 48 [38-84] & $42[18-72]$ & $54[18-84]$ & $0.1^{c}$ \\
\hline HOMA-\%B & $100.3[68.7-137.9]$ & $77.7[52.0-117.6]$ & $92.5[58.0-133.6]$ & $0.2^{c}$ \\
\hline HOMA-\%S & $111.0[64.1-138.4]$ & $124.4[75.9-286.5]$ & $99.6[62.8-279.7]$ & $0.1^{c}$ \\
\hline Sedentary lifestyle & $133(59 \%)$ & $86(59 \%)$ & 47 (57 \%) & $0.8^{\mathrm{a}}$ \\
\hline Antihypertensive medication & $10(4 \%)$ & $6(4 \%)$ & $4(5 \%)$ & $0.8^{\mathrm{a}}$ \\
\hline \multicolumn{5}{|l|}{ MPP re-examination } \\
\hline Age (years) & $74[70-75]$ & 74 [71-75] & $74[70-75]$ & $0.5^{c}$ \\
\hline Active smoking & $32(14 \%)$ & $22(15 \%)$ & $10(12 \%)$ & $0.5^{\mathrm{a}}$ \\
\hline BMI $\left(\mathrm{kg} / \mathrm{m}^{2}\right)$ & $27.9+/-3.5$ & $27.4+/-3.3$ & $28.9+/-3.7$ & $0.002^{b}$ \\
\hline Systolic blood pressure (mmHg) & $148+/-20$ & $147+/-20$ & $151+/-21$ & $0.2^{b}$ \\
\hline Total cholesterol (mmol/L) & $5.1+/-1.1$ & $5.1+/-1.1$ & $4.9+/-1.0$ & $0.2^{\mathrm{b}}$ \\
\hline FPG (mmol/L) & $7.1+/-2.1$ & $7.0+/-2.0$ & $7.2+/-2.2$ & $0.5^{\mathrm{b}}$ \\
\hline LVM (g) & $202+/-63$ & $197+/-64$ & $212+/-58$ & $0.1^{\mathrm{b}}$ \\
\hline LVMI $\left(\mathrm{g} / \mathrm{m}^{2}\right)$ & $103+/-31$ & $101+/-32$ & $106+/-28$ & $0.2^{\mathrm{b}}$ \\
\hline EF (\%) & $60+/-9$ & $60+/-8$ & $62+/-10$ & $0.09^{b}$ \\
\hline E/é & $10[7-12]$ & $8[7-10]$ & $13[12-15]$ & $<0.0001^{\mathrm{c}}$ \\
\hline Time (years) & 28 [28-29] & 28 [27-29] & $28[25-28]$ & $0.02^{c}$ \\
\hline
\end{tabular}

Categorical variables (active smoking) are given as $\mathrm{n}(\%)$, whereas continuous variables are given as mean $+/-$ SD (approximately normally distributed variables, i.e. body mass index (BMI), systolic blood pressure, total cholesterol, creatinine, fasting blood glucose (FBG), fasting plasma glucose (FPG), left ventricular mass (LVM), left ventricular mass index (LVMI), ejection fraction (EF)) or median (IQR) (non-normally distributed variables, i.e. age, insulin, HOMA-\%S, HOMA-\%B, E/é, and time)

${ }^{\mathrm{a}}$ Pearson's $\mathrm{X}^{2}$-test; ${ }^{\mathrm{b}}$ independent samples t-test; ${ }^{\mathrm{c}}$ Mann-Whitney $\mathrm{U}$ test

[21]. Subjects were age-wise comparable to our cohort; however, insulin sensitivity was derived by frequent sampling during OGTT. Likewise, Sundström et al. [22] found a borderline significant association between insulin resistance according to HOMA (HOMA-IR) and LVMI in normotensive subjects, but they did not adjust for glucometabolic status. On the contrary, in one of the largest studies to date, based on the Framingham Heart Study [10] cohort, HOMA-IR was associated with increased LVM among women only, although the relationship was largely accounted for by obesity. Further supporting our results, neither Galvan et al. [11] nor Ebinc et al. [23] were able to detect an association between LVM and insulin resistance, independently of BMI, in subjects without DM. Although a number of other studies exist, direct comparison is challenging, especially due to limited sample sizes and heterogeneous study populations, with the majority having assessed subjects already at increased cardiovascular risk, i.e. subjects who were obese, had DM, or were hypertensive. Such individuals have greater insulin resistance and LVM than the general population [24, 25], providing limited pathophysiological understanding regarding subjects in whom non-hemodynamic LVH-inducing mechanisms are likely to be more important. Adjustment for these important confounders has also been quite variable [11]; for instance, some of the described relations of insulin resistance to LVM may have been mainly due to the effects of blood pressure. A true association between insulin LV size and function is therefore more likely be revealed in a general population-based study.

Asymptomatic LV diastolic dysfunction is the most prominent characteristic of diabetic cardiomyopathy $[8,26]$. However, since LV diastolic function may 
Table 4 Multivariable linear regression model for the prediction of LVM at follow-up (adjusted ${ }^{2}=0.088$ )

\begin{tabular}{lll}
\hline Risk factor & $\beta$-coefficient $(95 \% \mathrm{Cl})$ & $P$-value \\
\hline Age (per year) & $0.10(-1.84$ to 2.05$)$ & 0.9 \\
BMI (per $\left.\mathrm{kg} / \mathrm{m}^{2}\right)$ & $6.69(4.05$ to 9.33$)$ & $<0.0001$ \\
HOMA-\%S Q1 vs. Q2-4 & $-12.46(-30.19$ to 5.27$)$ & 0.17 \\
\hline
\end{tabular}

already be impaired in the pre-diabetic or even preclinical phase of glucometabolic disturbances, i.e. before the onset of sustained hyperglycemia, an independent mechanistic role of insulin resistance may exist [27-29]. Furthermore, LV diastolic dysfunction may be evident at less severe insulin resistance when compared to the values associated with measureable LV structural changes [30]. In a population-based study including 1063 subjects, FontesCarvalho et al. found a significant association between higher insulin resistance according to HOMA-IR and worse LV diastolic function, including lower lateral é velocity and higher E/é ratio [31]; however, without adjusting for systolic blood pressure and BMI. Further supporting these results, both Dinh et al. [32] and Hwang et al. [30] found an independent association between insulin resistance and both presence and severity of LV diastolic dysfunction, independently of overt DM; however, neither studies adjusted for body size. In addition, all the above mentioned studies were cross-sectional. In the present study, we showed that BMI itself, but not insulin sensitivity, was significantly associated with E/é and grade 2 or 3 diastolic dysfunction, in multivariable analysis. Nevertheless, direct comparison between different studies is complicated by use of variable methods for assessment of both LV diastolic function and insulin sensitivity as well as inadequate adjustment for relevant confounders.

The highly prevalent co-existence of insulin resistance, hyperinsulinemia, obesity, hypertension, and DM makes it difficult to dissect the separate role of each of these conditions for development of subclinical cardiac damage [11]. However, at present time, there is insufficient convincing evidence to conclude that LVM and prevalence of LV diastolic dysfunction are greater among subjects with low insulin sensitivity or insulin resistance, when adequate care is taken to adjust for DM, blood pressure, and body size. Therefore, uncertainty remains, as to why subjects with increased body size have greater LV size and worse diastolic function [33-35]. Several

Table 5 Multivariable linear regression model for the prediction of LVMI at follow-up (adjusted $r^{2}=0.040$ )

\begin{tabular}{lll}
\hline Risk factor & $\beta$-coefficient $(95 \% \mathrm{Cl})$ & $P$-value \\
\hline Age (per year) & $0.37(-0.61$ to 1.36$)$ & 0.5 \\
BMI (per kg/m²) & $2.24(0.91$ to 3.58$)$ & 0.001 \\
HOMA-\%S Q1 vs. Q2-4 & $-5.18(-14.17$ to 3.799$)$ & 0.3 \\
\hline
\end{tabular}

Table 6 Multivariable linear regression model for the prediction of log(E/é) at follow-up (adjusted $r^{2}=0.152$ )

\begin{tabular}{llc}
\hline Risk factor & $\beta$-coefficient $(95 \% \mathrm{Cl})$ & $P$-value \\
\hline Age (per year) & $0.02(0.006$ to 0.027$)$ & 0.003 \\
BMl (per $\left.\mathrm{kg} / \mathrm{m}^{2}\right)$ & $0.03(0.02$ to 0.04$)$ & $<0.0001$ \\
Creatinine & $0.002(-0.001$ to 0.005$)$ & 0.18 \\
Time (per year) & $-0.03(-0.06$ to -0.01$)$ & 0.01 \\
HOMA-\%S Q1 vs. Q2-4 & $-0.04(-0.13$ to 0.06$)$ & 0.5 \\
\hline
\end{tabular}

other risk factors, e.g. elevated blood pressure, glucose and cholesterol levels, are associated with obesity, and the progressive addition of metabolic risk factors seems to be associated with greater LVM [36]. Just as proposed for diabetic cardiomyopathy, the myocardial alterations associated with obesity are likely to be a result of several similar synergistically acting mechanisms [8], and it is possible that low insulin sensitivity, as previously suggested for fasting plasma glucose [20], primarily acts as an effect modifier of these other risk factors. This hypothesis is supported by the fact that most studies reporting a positive association between insulin resistance and subclinical cardiac damage have involved subjects with other risk factors as well, and our chances of finding positive associations were weakened by the strict selection criteria employed, aiming to exclude subjects with prevalent DM or cardiovascular disease. Although we were not directly able to find synergistic interactions between insulin sensitivity and the traditional risk factors in the present study, this could have resulted from the relatively small sample size. The exact reason why baseline BMI, but not insulin sensitivity, was associated with later cardiac damage in our study, is uncertain. However, HOMA-indices display pronounced biological variation, which decreases the chances of finding such significant associations. Furthermore, the HOMA-indices show considerable temporal changes, which may further reduce the predictive value at long-term follow-up. Although BMI changes over time as well, the fluctuations may more often be unidirectional [37, 38].

Regardless of whether or not insulin resistance is the main mediator of subclinical cardiac damage in obesity, pre-diabetes, and DM, the strong association between higher baseline BMI and later detection of structural

Table 7 Binary logistic regression model for the prediction of grade 2 or 3 diastolic dysfunction at follow-up (Nagelkerke $\left.r^{2}=0.078\right)$

\begin{tabular}{llc}
\hline Risk factor & Odds ratio $(95 \% \mathrm{Cl})$ & $P$-value \\
\hline Age (per year) & $1.03(0.94$ to 1.13$)$ & 0.5 \\
BMI (per $\left.\mathrm{kg} / \mathrm{m}^{2}\right)$ & $1.12(1.01$ to 1.24$)$ & 0.03 \\
Time (per year) & $0.86(0.73$ to 1.02$)$ & 0.07 \\
HOMA-\%S Q1 vs. Q2-4 & $1.30(0.66$ to 2.56$)$ & 0.4 \\
\hline
\end{tabular}


and functional LV changes in our study suggests that early weight loss in overweight or obese subjects may halt the progression of adverse cardiac alterations, specifically reduce the risk of $\mathrm{LVH}$ and diastolic dysfunction. This is supported by the results from the Coronary Artery Risk Development in Young Adults study, in which increasing BMI over a 5- to 10-year follow-up in generally healthy adults was associated with increasing LVM [33, 34]. Further supporting this early preventive strategy is the weak ability of therapeutic interventions, e.g. intensive glycemic control $[39,40]$ and antihypertensive drugs $[41,42]$, to lower cardiovascular risk, when DM is overt, because the myocardial damage may have become partly to completely irreversible at this point. Lastly, early weight loss is associated with other clinically relevant benefits, including a lower risk of hypertension, dyslipidemia, and DM itself, which may further reduce the risk of cardiovascular complications [43]. The lack of our detection of a beneficial effect of BMI reduction in the present study was most likely related to the small number $(n=32)$ of subjects who actually lost weight during the study period and the possible BMI fluctuations over time that we were unable to account for. Even in those having lost weight, the loss was very subtle in most subjects. In addition, most individuals were normo- or overweight, but not obese, making detection of substantial benefits difficult.

\section{Limitations}

Although the participation rates of $71 \%$ in MPP and $72 \%$ in MPP-RES, respectively, are considered high, one may still argue that the study subjects did not represent a truly random population sample since people who agree to take part may be healthier than the general population. All subjects in the present study were male, limiting the applicability of the results in females. Moreover, our exclusion of a vast amount of the original study population in order to get a cohort of apparently healthy subjects, who were alive and underwent echocardiography, however with variable follow-up periods, may introduce further selection bias, including survival bias, and lack of adequate power.

Insulin sensitivity was not assessed according to the gold standard method, i.e. the hyperinsulinemic euglycemic clamp technique [44]. However, the use of fasting BG and insulin was justified by the fact that HOMA-derived parameters are strongly related to clamp-measured insulin sensitivity and insulin resistance in subjects both with and without DM [27, 45]. Sensitivity analyses with respect to the prediction of LV size and LV diastolic dysfunction were performed, before settling on the use of Q1 as cut-off in the present study. Moreover, data on glucose tolerance would have been desirable; however, in the present study, inclusion of these data would have reduced sample size even further.

Similarly, the use of BMI as a surrogate marker for obesity has some limitations [46-48], and the inclusion of other measures, e.g. waist circumference and waistto-hip ratio would have been preferred; however, these measurements were not available. The accuracy of BMI for diagnosing obesity is especially limited for individuals with BMI between 25.0 and $29.9 \mathrm{~kg} / \mathrm{m}^{2}$, in men and in the elderly. However, BMI or plain body weight may still be the best way to evaluate changes in body fat content over time, because increments in body weight or BMI most likely represent fat gain [49].

Linear LV measurements have prognostic value and are feasible, especially when studying large populations. However, the method is based solely on basal dimensions, unable to accommodate for LV shape and size changes that might occur along the long axis of the chamber, and the formula for calculating LVM assumes normal LV geometry and cubes the linear measurements. Therefore, even small errors may significantly influence the calculated mass [17]. Although echocardiography does not directly measure the same parameters for diastolic function that are measured invasively, it is still the most practical and recommended routine clinical approach. However, some limitations deserve mentioning. Minimal angulation is essential for reliable spectral Doppler measurements. Additionally, the usefulness of é velocity in normal subjects may be limited, as preload increases é in these subjects. The correlation between $\mathrm{E} / \mathrm{e}$ between 8 and 15 using septal é (9-13 in the present study) and mean LV diastolic pressure displays wide variability [50]. Therefore, although increased E/é is indicative of an elevated LV filling pressure, it should not be used as stand-alone parameter when drawing conclusions about LV diastolic dysfunction. Furthermore, our grading of LV diastolic dysfunction could have been more robust, had we also been able to incorporate the left atrial volume index [19]. Lastly, the lack of an echocardiography at baseline prevented us from directly assessing LV structural and functional changes over time.

\section{Conclusion}

In conclusion, in a prospective population-based cohort study including apparently healthy middle-aged male subjects, greater baseline BMI, but not lower insulin sensitivity was independently associated with greater LVM and diastolic dysfunction at long-term follow-up.

\section{Ethics, consent and permissions}

All subjects provided informed consent to participate in this study. 


\section{Additional file}

Additional file 1: Table S1. Baseline characteristics according to BMI category. (DOCX $17 \mathrm{~kb}$ )

\section{Abbreviations}

BMl: Body mass index; BSA: Body surface area; DM: Diabetes mellitus; DT: E-wave deceleration time; ECG: Electrocardiography; FBG: Fasting blood glucose; FPG: Fasting plasma glucose; HOMA: Homeostatic model assessment; ICD: International classification of diseases; IQR: Interquartile range; LV: Left ventricular / left ventricle; LVEF: Left ventricular ejection fraction; LVH: Left ventricular hypertrophy; LVM: Left ventricular mass; LVMI: Left ventricular mass index; MPP: Malmö preventive project; MPPRES: Malmö preventive project re-examination study; OGTT: Oral glucose tolerance test; WHO: World Health Organization.

\section{Competing interest}

All authors have completed the Unified Competing Interest form at www.icmje.org/coi_disclosure.pdf (available on request from the corresponding author) and declare: no support from any organization for the submitted work; no financial relationship with any organizations that might have an interest in the submitted work in the previous 3 years; no other relationships or activities that could appear to have influenced the submitted work.

\section{Authors' contribution}

MN contributed substantially to the conception of the hypothesis, the design of the work, analysis of the work, interpretation of data for the work, drafting the work, critical revision for important intellectual content, final approval of the version to be published, and agrees to be accountable for all aspects of the work in ensuring that questions related to the accuracy or integrity of any part of the work are appropriately investigated and resolved. MP contributed substantially to the conception of the hypothesis, the design of the work, analysis of the work, interpretation of data for the work, drafting the work, critical revision for important intellectual content, final approval of the version to be published, and agrees to be accountable for all aspects of the work in ensuring that questions related to the accuracy or integrity of any part of the work are appropriately investigated and resolved. OG contributed substantially to the analysis of the work, interpretation of data for the work, critical revision for important intellectual content, the final approval of the version to be published, and agrees to be accountable for all aspects of the work in ensuring that questions related to the accuracy or integrity of any part of the work are appropriately investigated and resolved. ML contributed substantially to the acquisition of data for the work, critical revision for important intellectual content, the final approval of the version to be published, and agrees to be accountable for all aspects of the work in ensuring that questions related to the accuracy or integrity of any part of the work are appropriately investigated and resolved. PN contributed substantially to the acquisition of data for the work, the interpretation of data for the work, critical revision for important intellectual content, final approval of the version to be published, and agrees to be accountable for all aspects of the work in ensuring that questions related to the accuracy or integrity of any part of the work are appropriately investigated and resolved. $\mathrm{MO}$ contributed substantially to the conception of the hypothesis, the design of the work, analysis of the work, interpretation of data for the work, drafting the work, critical revision for important intellectual content, final approval of the version to be published, and agrees to be accountable for all aspects of the work in ensuring that questions related to the accuracy or integrity of any part of the work are appropriately investigated and resolved. All authors read and approved the final manuscript.

\section{Acknowledgements}

This study was funded by The Danish Diabetes Academy supported by the Novo Nordisk Foundation.

All authors take responsibility for all aspects of the reliability and freedom from bias of the data presented and their discussed interpretation.

\section{Author details}

${ }^{1}$ Cardiovascular and Metabolic Preventive Clinic, Department of Endocrinology, Centre for Individualized Medicine in Arterial Diseases (CIMA), Odense University Hospital, Sdr. Boulevard 29, DK-5000 Odense, Denmark.
${ }^{2}$ Department of Nuclear Medicine, Odense University Hospital, Odense and Centre of Health Economics Research, University of Southern Denmark, Odense, Denmark. ㄹDepartment of Cardiology, Skåne University Hospital, Malmö, Sweden. ${ }^{4}$ Department of Clinical Sciences, Lund University, Skåne University Hospital, Malmö, Sweden. ${ }^{5}$ Hypertension in Africa Research Team (HART), North-West University, Potchefstroom, South Africa.

Received: 1 October 2015 Accepted: 4 December 2015

Published online: 10 December 2015

\section{References}

1. Zile MR, Baicu CF, Bonnema DD. Diastolic heart failure: definitions and terminology. Prog Cardiovasc Dis. 2005;47(5):307-13.

2. Wan SH, Vogel MW, Chen HH. Pre-clinical diastolic dysfunction. J Am Coll Cardiol. 2014;63(5):407-16

3. Verdecchia P, Carini G, Circo A, Dovellini E, Giovannini E, Lombardo M, et al. Left ventricular mass and cardiovascular morbidity in essential hypertension: the MAVI study. J Am Coll Cardiol. 2001;38(7):1829-35.

4. Kane GC, Karon BL, Mahoney DW, Redfield MM, Roger VL, Burnett Jr JC, et al. Progression of left ventricular diastolic dysfunction and risk of heart failure. JAMA. 2011;306(8):856-63.

5. Kiencke S, Handschin R, von Dahlen R, Muser J, Brunner-Larocca HP, Schumann J, et al. Pre-clinical diabetic cardiomyopathy: prevalence, screening, and outcome. Eur J Heart Fail. 2010;12(9):951-7.

6. From AM, Scott CG, Chen HH. Changes in diastolic dysfunction in diabetes mellitus over time. Am J Cardiol. 2009;103(10):1463-6.

7. From AM, Scott CG, Chen HH. The development of heart failure in patients with diabetes mellitus and pre-clinical diastolic dysfunction a populationbased study. J Am Coll Cardiol. 2010;55(4):300-5.

8. Boudina S, Abel ED. Diabetic cardiomyopathy revisited. Circulation. 2007;115(25):3213-23.

9. Paolisso G, Galderisi M, Tagliamonte MR, de Divitis M, Galzerano D, Petrocelli A, et al. Myocardial wall thickness and left ventricular geometry in hypertensives. Relationship with insulin. Am J Hypertens. 1997;10(11):1250-6.

10. Rutter MK, Parise H, Benjamin EJ, Levy D, Larson MG, Meigs JB, et al. Impact of glucose intolerance and insulin resistance on cardiac structure and function: sex-related differences in the Framingham Heart Study. Circulation. 2003;107(3):448-54.

11. Galvan AQ, Galetta F, Natali A, Muscelli E, Sironi AM, Cini G, et al. Insulin resistance and hyperinsulinemia: no independent relation to left ventricular mass in humans. Circulation. 2000;102(18):2233-8.

12. Rerkpattanapipat $P, D^{\prime}$ Agostino Jr RB, Link KM, Shahar E, Lima JA, Bluemke $D A$, et al. Location of arterial stiffening differs in those with impaired fasting glucose versus diabetes: implications for left ventricular hypertrophy from the Multi-Ethnic Study of Atherosclerosis. Diabetes. 2009:58(4):946-53.

13. Berglund G, Nilsson P, Eriksson KF, Nilsson JA, Hedblad B, Kristenson H, et al. Long-term outcome of the Malmo preventive project: mortality and cardiovascular morbidity. J Intern Med. 2000;247(1):19-29.

14. Carroll JJ, Smith N, Babson AL. A colorimetric serum glucose determination using hexokinase and glucose-6-phosphate dehydrogenase. Biochem Med. 1970:4(2):171-80.

15. Eriksson KF, Lindgarde F. Impaired glucose tolerance in a middle-aged male urban population: a new approach for identifying high-risk cases. Diabetologia. 1990:33(9):526-31.

16. Oxford Uo. HOMA calculator. 2004. [cited 2015 Apr 8]. Available from: https://www.dtu.ox.ac.uk/homacalculator/.

17. Lang RM, Badano LP, Mor-Avi V, Afilalo J, Armstrong A, Ernande L, et al. Recommendations for cardiac chamber quantification by echocardiography in adults: an update from the American Society of Echocardiography and the European Association of Cardiovascular Imaging. J Am Soc Echocardiogr. 2015:28(1):1-39. e14.

18. Leosdottir M, Willenheimer R, Plehn J, Borgquist R, Gudmundsson P, Harris TB, et al. Myocardial structure and function by echocardiography in relation to glucometabolic status in elderly subjects from 2 population-based cohorts: a cross-sectional study. Am Heart J. 2010;159(3):414-20. e4.

19. Nagueh SF, Appleton CP, Gillebert TC, Marino PN, Oh JK, Smiseth OA, et al. Recommendations for the evaluation of left ventricular diastolic function by echocardiography. J Am Soc Echocardiogr. 2009;22(2):107-33.

20. Pareek M, Nielsen ML, Gerke O, Leosdottir M, Moller JE, Hindersson P, et al. Worsening diastolic function is associated with elevated fasting plasma 
glucose and increased left ventricular mass in a supra-additive fashion in an elderly, healthy, Swedish population. Int J Cardiol. 2015;184:466-72.

21. Phillips RA, Krakoff LR, Dunaif A, Finegood DT, Gorlin R, Shimabukuro S. Relation among left ventricular mass, insulin resistance, and blood pressure in nonobese subjects. J Clin Endocrinol Metab. 1998;83(12):4284-8.

22. Sundstrom J, Arnlov J, Stolare K, Lind L. Blood pressure-independent relations of left ventricular geometry to the metabolic syndrome and insulin resistance: a population-based study. Heart. 2008;94(7):874-8.

23. Ebinc H, Ebinc FA, Ozkurt ZN, Dogru T, Yilmaz M. Relationship of left ventricular mass to insulin sensitivity and body mass index in healthy individuals. Acta Cardiol. 2006;61 (4):398-405

24. Aronne LU, Segal KR. Adiposity and fat distribution outcome measures: assessment and clinical implications. Obes Res. 2002;10 Suppl 1:14S-21S

25. Defronzo RA, Ferrannini E. Insulin resistance. A multifaceted syndrome responsible for NIDDM, obesity, hypertension, dyslipidemia, and atherosclerotic cardiovascular disease. Diabetes Care. 1991;14(3):173-94.

26. Raev DC. Which left ventricular function is impaired earlier in the evolution of diabetic cardiomyopathy? An echocardiographic study of young type I diabetic patients. Diabetes Care. 1994:17(7):633-9.

27. Bonora E, Kiechl S, Willeit J, Oberhollenzer F, Egger G, Meigs JB, et al. Population-based incidence rates and risk factors for type 2 diabetes in white individuals: the Bruneck study. Diabetes. 2004;53(7):1782-9.

28. Stahrenberg R, Edelmann F, Mende M, Kockskamper A, Dungen HD, Scherer M, et al. Association of glucose metabolism with diastolic function along the diabetic continuum. Diabetologia. 2010;53(7):1331-40.

29. Bajraktari G, Koltai MS, Ademaj F, Rexhepaj N, Qirko S, Ndrepepa G, et al. Relationship between insulin resistance and left ventricular diastolic dysfunction in patients with impaired glucose tolerance and type 2 diabetes. Int J Cardiol. 2006;110(2):206-11.

30. Hwang YC, Jee JH, Kang M, Rhee EJ, Sung J, Lee MK. Metabolic syndrome and insulin resistance are associated with abnormal left ventricular diastolic function and structure independent of blood pressure and fasting plasma glucose level. Int J Cardiol. 2012;159(2):107-11.

31. Fontes-Carvalho R, Ladeiras-Lopes R, Bettencourt P, Leite-Moreira A, Azevedo A. Diastolic dysfunction in the diabetic continuum : association with insulin resistance, metabolic syndrome and type 2 diabetes. Cardiovasc Diabetol. 2015;14(1):4.

32. Dinh W, Lankisch M, Nickl W, Scheyer D, Scheffold T, Kramer F, et al. Insulin resistance and glycemic abnormalities are associated with deterioration of left ventricular diastolic function: a cross-sectional study. Cardiovasc Diabetol. 2010;9:63.

33. Gardin JM, Brunner D, Schreiner PJ, Xie X, Reid CL, Ruth $K$, et al. Demographics and correlates of five-year change in echocardiographic left ventricular mass in young black and white adult men and women: the Coronary Artery Risk Development in Young Adults (CARDIA) study. J Am Coll Cardiol. 2002;40(3):529-35.

34. Lorber R, Gidding SS, Daviglus ML, Colangelo LA, Liu K, Gardin JM. Influence of systolic blood pressure and body mass index on left ventricular structure in healthy African-American and white young adults: the CARDIA study. J Am Coll Cardiol. 2003;41 (6):955-60.

35. Russo C, Jin Z, Homma S, Rundek T, Elkind MS, Sacco RL, et al. Effect of obesity and overweight on left ventricular diastolic function: a communitybased study in an elderly cohort. J Am Coll Cardiol. 2011:57(12):1368-74.

36. de Simone G, Palmieri V, Bella JN, Celentano A, Hong Y, Oberman A, et al. Association of left ventricular hypertrophy with metabolic risk factors: the HyperGEN study. J Hypertens. 2002;20(2):323-31.

37. Jayagopal V, Kilpatrick ES, Jennings PE, Hepburn DA, Atkin SL. Biological variation of homeostasis model assessment-derived insulin resistance in type 2 diabetes. Diabetes Care. 2002;25(11):2022-5.

38. Sarafidis PA, Lasaridis AN, Nilsson PM, Pikilidou MI, Stafilas PC, Kanaki A, et al. Validity and reproducibility of HOMA-IR, 1/HOMA-IR, QUICKI and McAuley's indices in patients with hypertension and type II diabetes. J Hum Hypertens. 2007;21(9):709-16.

39. Action to Control Cardiovascular Risk in Diabetes Study G, Gerstein HC, Miller ME, Byington RP, Goff Jr DC, Bigger JT, et al. Effects of intensive glucose lowering in type 2 diabetes. N Engl J Med. 2008;358(24):2545-59.

40. Group AC, Patel A, MacMahon S, Chalmers J, Neal B, Billot L, et al. Intensive blood glucose control and vascular outcomes in patients with type 2 diabetes. N Engl J Med. 2008;358(24):2560-72.

41. Gerdts E, Okin PM, Omvik P, Wachtell K, Dahlof B, Hildebrandt P, et al. Impact of diabetes on treatment-induced changes in left ventricular structure and function in hypertensive patients with left ventricular hypertrophy. The LIFE study. Nutr Metab Cardiovasc Dis. 2009;19(5):306-12.

42. Okin PM, Devereux RB, Gerdts E, Snapinn SM, Harris KE, Jern S, et al. Impact of diabetes mellitus on regression of electrocardiographic left ventricular hypertrophy and the prediction of outcome during antihypertensive therapy: the Losartan Intervention For Endpoint (LIFE) Reduction in Hypertension Study. Circulation. 2006;113(12):1588-96.

43. Oster G, Thompson D, Edelsberg J, Bird AP, Colditz GA. Lifetime health and economic benefits of weight loss among obese persons. Am J Public Health. 1999;89(10):1536-42.

44. Defronzo RA, Tobin JD, Andres R. Glucose clamp technique: a method for quantifying insulin secretion and resistance. Am J Physiol. 1979;237(3):E214-23.

45. Hanley AJ, Williams K, Stern MP, Haffner SM. Homeostasis model assessment of insulin resistance in relation to the incidence of cardiovascular disease: the San Antonio Heart Study. Diabetes Care. 2002;25(7):1177-84.

46. Romero-Corral A, Somers VK, Sierra-Johnson J, Jensen MD, Thomas RJ, Squires $\mathrm{RW}$, et al. Diagnostic performance of body mass index to detect obesity in patients with coronary artery disease. Eur Heart J. 2007;28(17):2087-93.

47. Frankenfield DC, Rowe WA, Cooney RN, Smith JS, Becker D. Limits of body mass index to detect obesity and predict body composition. Nutrition. 2001;17(1):26-30.

48. Piers LS, Soares MJ, Frandsen SL, O'Dea K. Indirect estimates of body composition are useful for groups but unreliable in individuals. Int J Obes Relat Metab Disord. 2000;24(9):1145-52.

49. Romero-Corral A, Somers VK, Sierra-Johnson J, Thomas RJ, Collazo-Clavell $\mathrm{ML}$, Korinek J, et al. Accuracy of body mass index in diagnosing obesity in the adult general population. Int J Obes (Lond). 2008;32(6):959-66.

50. Ommen SR, Nishimura RA, Appleton CP, Miller FA, Oh JK, Redfield MM, et al. Clinical utility of Doppler echocardiography and tissue Doppler imaging in the estimation of left ventricular filling pressures: a comparative simultaneous Doppler-catheterization study. Circulation. 2000;102(15):1788-94.

\section{Submit your next manuscript to BioMed Central and we will help you at every step:}

- We accept pre-submission inquiries

- Our selector tool helps you to find the most relevant journal

- We provide round the clock customer support

- Convenient online submission

- Thorough peer review

- Inclusion in PubMed and all major indexing services

- Maximum visibility for your research

Submit your manuscript at www.biomedcentral.com/submit
C Biomed Central 